\title{
colaboraciones
}

El autor de esta colaboración, Dr. Arquitecto Vicente Mas, ha dirigido durante los últimos años esta Revista y desea a través de estas páginas reflejar su impre sión acerca de la vida de INFORMES.
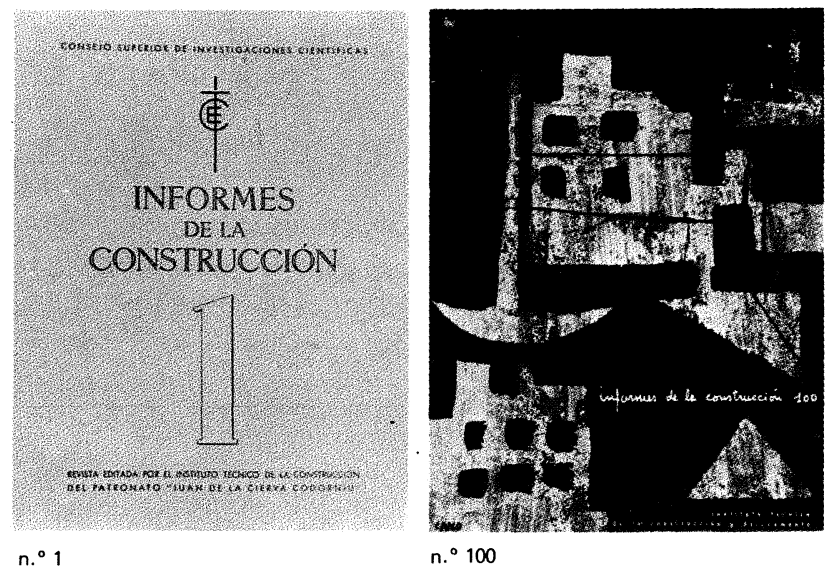

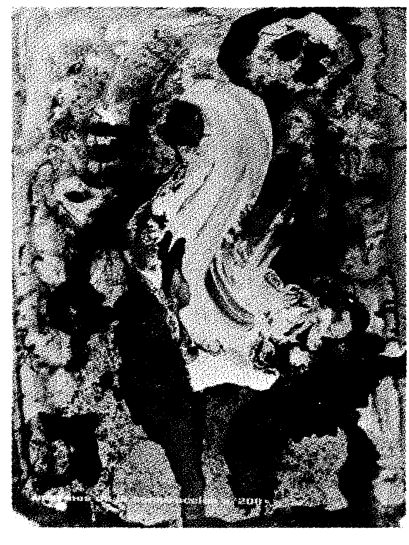

n. ${ }^{\circ} 200$

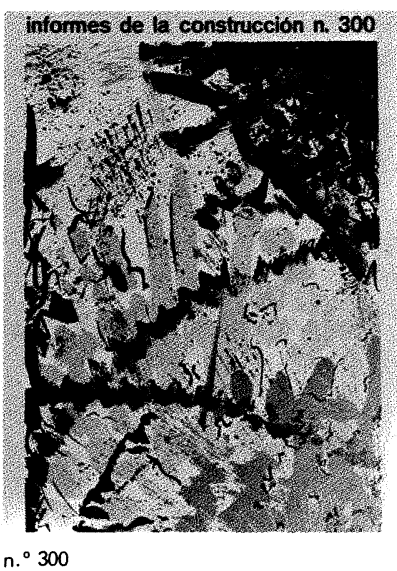

\section{INFORMES DE LA CONSTRUCCION: DE AYER A HOY}

\author{
Vicente Mas Sarrió, Dr. Arquitecto \\ 071-12
}

Informes de la Construcción es una revista mensual que ha estado dedicada a difundir todos y cada uno de los sectores del ámbito a lo largo de casi un tercio de siglo, circunstancia que avala, por si misma, una continuidad de garantia digna de ser considerada seriamente.

Durante todos estos años ha pasado revista y ha expuesto, a varios miles de lectores del mundo entero, la panorámica general y la singularidad española, así como la de la mayor parte de los paises del globo, en este campo de la construcción que comprende a más de la octava parte del colectivo laboral de cada nación, además de una muy significativa representación de los sectores secundario y terciario del empresariado nacional respectivo.

Toda la información que puede aportar datos interesantes a los conocimientos progresivos $y$ actuales, en cada momento, sobre el tema ha sido acogida mes tras mes por nuestra Revista, en la que han vertido su saber, sus investiga- ciones y su experiencia, tanto el personal investigador del Instituto Eduardo Torroja, como los prestigiosos colaboradores extranjeros que, espontáneamente $o$ a requerimiento de los sucesivos Directores de Informes de la Construcción, han tenido la amabilidad de atendernos, sabedores de la pulcritud de presentación, perfección de interpretación y gran difusión de que siempre hizo gala este medio informativo, el más vistoso y ostensible de nuestro Instituto, y tal vez del Consejo Superior de Investigaciones Científicas, de España, al que pertenece.

Hacemos notar aquí y ahora, precisamente, que si bien la Revista no ha cambiado su denominación original: "Informes de la Construcción", el Organismo en el cual nació ha tenido los siguientes nombres: primero "Instituto Técnico de la Construcción», después "Instituto Técnico de la Construcción y del Cementon y finalmente, hasta hoy, "Instituto Eduardo Torroja de la Construcción y del Cementon, en honor de uno de sus preclaros fundadores.

En sus variados artículos, han ido apareciendo destacadas obras, casi siempre acabadas, de arquitectura e ingenieria, secciones de fichas técnicas de maquinaria, de fabricantes y de información comercial del ramo, asi como recomendaciones de gran utilidad, bajo la denominación general de "Datos de Proyecto" - hoteles, restaurantes, transportes - además de ábacos y tablas de uso en gabinete o estudio 


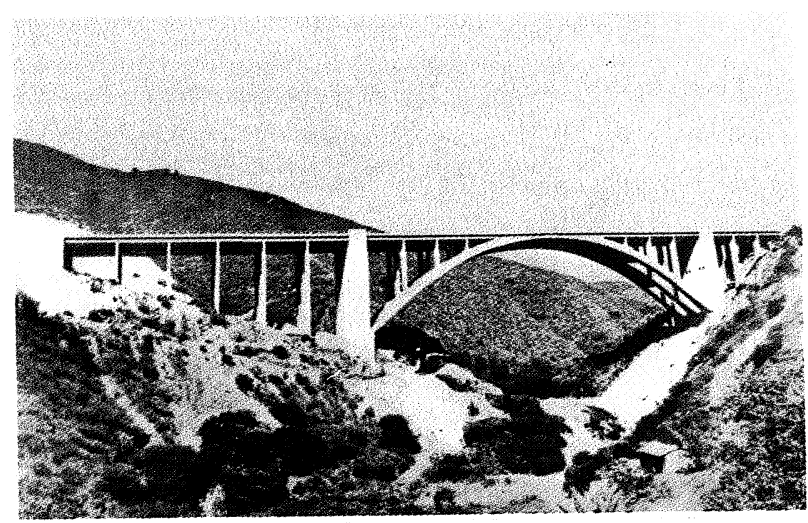

Freyssinet.-Autopista Caracas-La Guaira (Informes n. ${ }^{\circ} 54$ ).

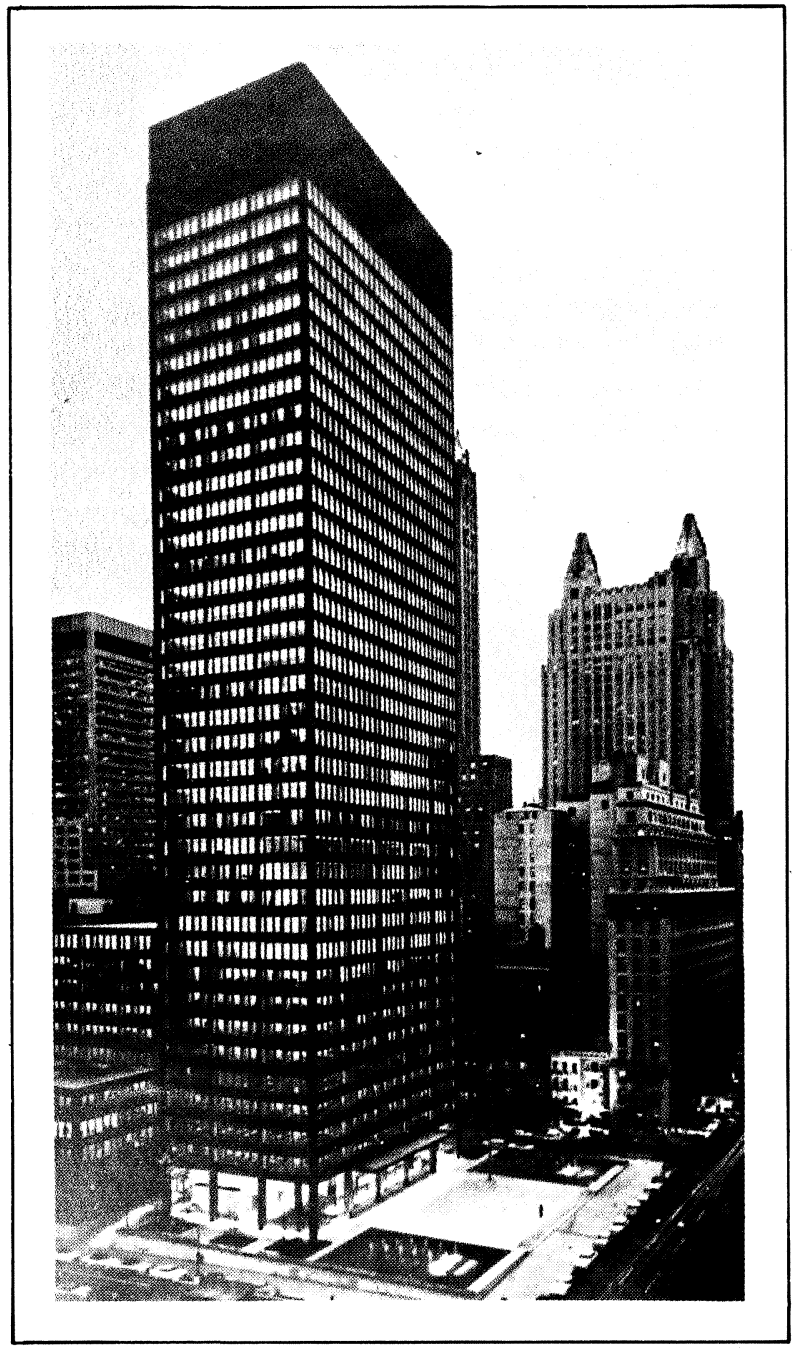

M. van der Rohe.-Edificio Seagram, en Nueva York IInfor mes $n .^{\circ} 1211$.
- soleamiento, estructuras, etc. -, los 128 Documentos de Idoneidad Técnica (DIT) sobre materiales, sistemas y procedimientos no tradicionales de construcción, que ha expedido el Centro, como sin duda ocurrirá con los otros 35 que tiene solicitados, hasta la fecha.

Asimismo, la acumulación sucesiva de diversos artículos del insigne Ingeniero español Carlos Fernández Casado y del mundialmente conocido Arquitecto norteamericano Richard J. Neutra, han dado como resultado - previamente concebido- tres documentados y eruditos libros sobre "Acueductos Romanos en España» e "Historia del Puente en España-Puentes Romanos" del primero, y "Richard J. Neutra", obviamente del segundo.

Año tras año, Informes de la Construcción ha ido renovándose y tratando de ocupar posiciones de vanguardia en todo cuanto le es concerniente: construcción y edificación. Ha cuidado por igual los aspectos estéticos, la presentación de soluciones funcionales, matemáticas o estructurales y la adecuada utilización de materiales y maquinaria, en la confianza de prestar un servicio de divulgación y eficaz ayuda a todos los estratos que viven y trabajan dentro del amplio espectro de estas ramas del saber, desde el científico hasta el público en general, a los cuales se les ha "hablado" en castellano, pero resumiéndoles el contenido de todas $y$ cada una de las exposiciones en diversos idiomas, a fin de facilitar su acceso a los lectores que nos han solicitado desde casi todas las partes del mundo.

A pesar de su constante evolución y modernización, en cuanto a formato, composición y temática se refiere, hay algo que no ha cambiado fundamentalmente desde sus balbuceos iniciales, una vez demostrada su eficacia por propios y extraños: la división del conjunto de cada número en dos partes, una de carácter informativo -obras prestigiosas de alto nivel arquitectónico y de ingenieria, avaladas por la calidad de su realización o por la fama nacional o internacional de sus autores, a quienes por su gran número y pareja categoría nos sería Imposible citar, amén de la imperdonable eventualidad de olvidar a alguno- y otra, eminentemente práctica, materializada en las hojas finales de bibliografía - brevemente recensadas - y en las diferentes fichas de temas varios, preparadas para poder ser archivadas. Igualmente, desde el primer número, se ha mantenido la numeración que encabeza cada artículo y que permite ordenarlos, para su fácil y cómoda consulta, 
Informes de la Construcción/327

por temas, de acuerdo con un indice que se ha facilitado al final de cada año.

Consideramos que Informes de la Construcción ha cumplido siempre, con regularidad razonable, la misión que se propuso de informar, en cualquier momento, con agilidad, concisión, actualidad y bello grafismo sobre todo aquello que el cada vez más exigente y más ocupado lector necesitaba para estar al día en temas de su competencia, así como servirse de la documentación proporcionada para crear nuevas y originales obras que apunten a la meta de calidad y perfección siempre deseables por el hombre en cualquier faceta de su hacer.

Informes de la Construcción ha seguido paso a paso, lustro tras lustro, la evolución que ha experimentado la especialidad que su mismo título expone, desde los sistemas más tradicionales - que no menos interesantes ni utilizados aún hoy, en nuestros días-, hasta los más avanzados que impone la moderna organización de obras, la seguridad en el trabajo, la legislación, la mecanización, la tecnologia depurada, los avances industriales sofisticados y en constante progreso y la utilización, cada vez más frecuente, de ordenadores electrónicos, aplicados ya a casi todos los aspectos pormenorizados y globales de las obras de edificación y públicas, tales como: viviendas, oficinas, escuelas, hospitales, centros religiosos, deportivos, naves industriales, espectáculos, hoteles, construcciones agrícolas, carreteras, túneles, presas, puentes, canales, torres de televisión y radio, aeropuertos, faros, grandes depósitos de agua, estaciones de autobuses y ferrocarril, plataformas marinas, estaciones depuradoras, gaseoductos, centrales hidrosolares, etcétera.

A sus páginas se han asomado espléndida y ampliamente documentadas, a fin de dejarse analizar con minuciosidad, construcciones de ladrillo, bloques, hormigón, hierro, aluminio, cobre, madera o plástico; sistemas tradicionales e industrializados; de concepción libre o planificados con arreglo a módulos severamente estudiados; mecánica del suelo, topografía, andamiajes, etc.

Todo ello ha sido presentado siempre con profusión de planos, detalles constructivos, expresivas fotografias y una explicación precisa, sin excesos farragosos ni prolijos, que pudiera tal vez agobiar al lector, cuya actividad profesional está frecuentemente ocupada por multitud de problemas y que tiende lógicamente a asimilar

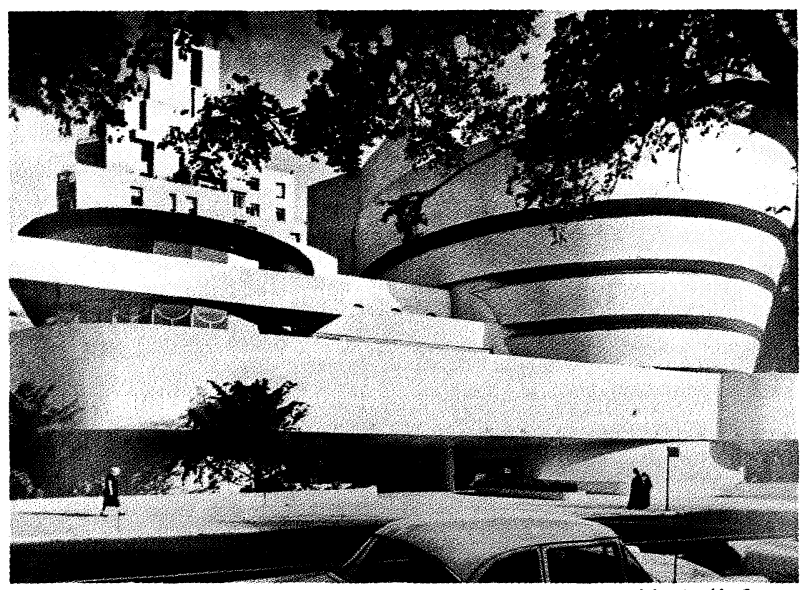

F. LI. Wright.-Museo Guggenheim, en Nueva York (Informes $n .^{\circ} 1211$.

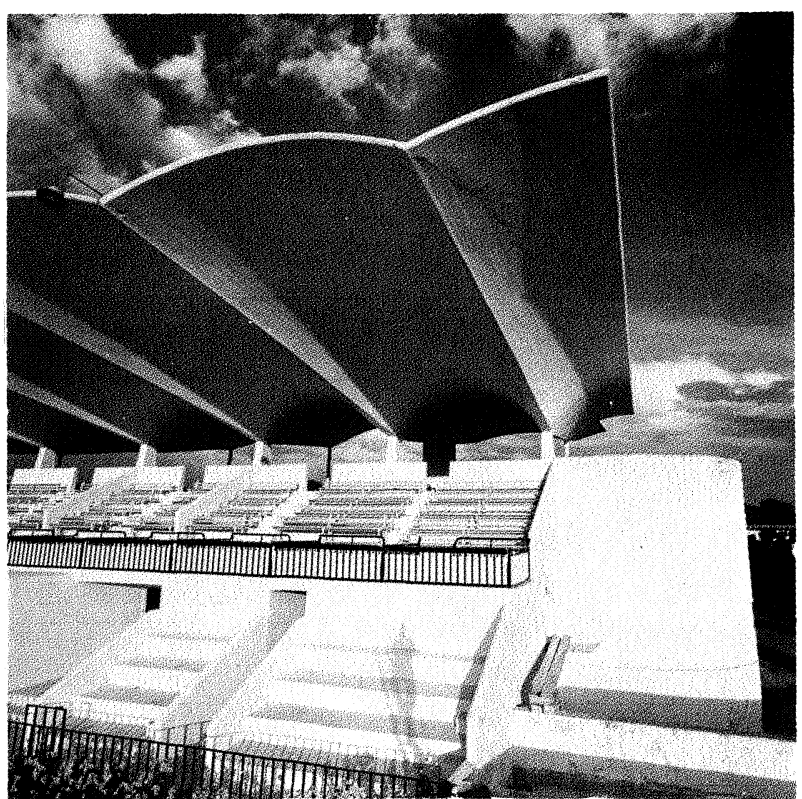

E. Torroja.-Hipódromo de La Zarzuela, en Madrid (Informes $n .^{\circ}$ 137).

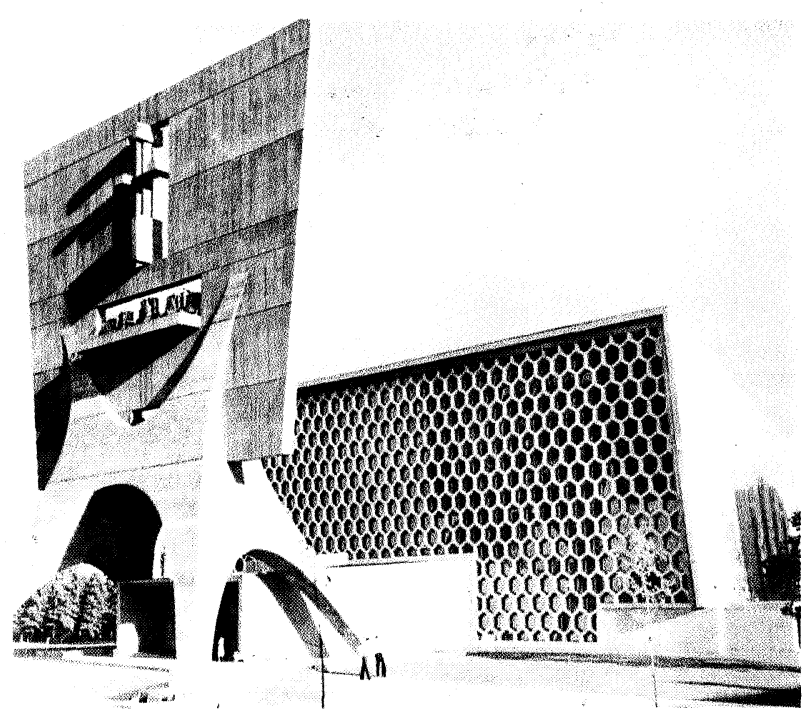

M. Breuer.-Abadía de San Juán, en Minnesota llnformes $n .^{\circ} 153$ ). 
ideas, conceptos y planos que le entren fácil y cómodamente por los ojos a fin de desarrollar, con posterioridad, su propio y original proyecto, en el que si tendrá necesidad de meditar, calcular y trabajar con detenimiento, basándose en aquellos datos que vio y que le fueron ofrecidos con la previsora intención de no cansarle previamente.

De igual forma, se ha puesto de manifiesto una preocupación constante por todo cuanto signifique calidad y ejercicio de controles diversos en la construcción, a través de múltiples y documentados artículos originales de autores del Instituto Eduardo Torroja, del resto de nuestra

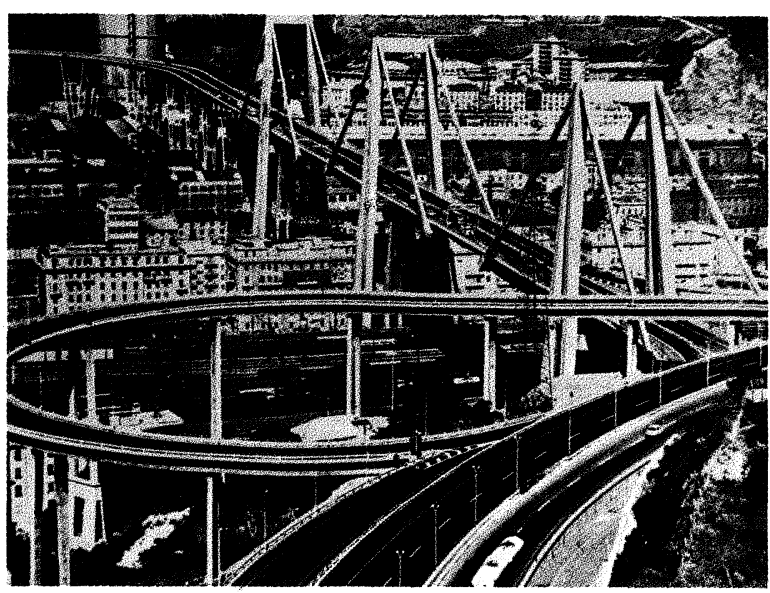

R. Morandi.-Viaducto, en Génova (Informes $n .^{\circ} 200$ ).

Nación y extranjeros, sin olvidar los temas siempre vigentes relativos al cálculo de estructuras, en todo su abanico de posibilidades, y al de la variedad de ensayos referidos a meteriales de construcción y elementos constructivos, tanto sobre modelos reducidos como a escala real.

Si la construcción, en general, y la edificación, en particular, han sido tratadas desde todos los puntos de vista posibles y con la minuciosidad y amplitud necesarias, en cuanto a obras de nueva planta se refiere, no menos atención merecieron, durante los 33 años, pasados, las obras e investigaciones originadas por reparaciones, restauración y conservación de las ya construidas, en especial de las más notables, por su importancia o valor artístico, que así lo requirieran.

Este capítulo, al que generalmente no se aprecia en su justo valor por parte de las revistas del ramo, es sin embargo considerable y de tal importancia que los gastos por él originados equivalen a un porcentaje de inversión cifrado estadisticamente entre un tercio y dos quintos del montante total, destinado a la construcción, en cualquier país desarrollado.

Enlaza esto, puntualmente, con el tema de la patologia de todo tipo de obras, al que Informes de la Construcción ha dedicado versados artículos - también de autores españoles y de otros paises - conocedores de que tanto el promotor como el constructor, el técnico o el usuario olvidan, con frecuencia, que las obras acabadas viven en un determinado ambiente $y$ se comportan ecológicamente en él, sufriendo toda suerte de efectos por causas tan diversas como son: la climatología (dilataciones, contracciones, humedades, heladicidad...), las cargas, el envejecimiento, la acción próxima y a distancia de la vegetación (cambios de microclímas, absorción de agua con posibles alteraciones dinámicas del suelo, etc.). Esta última afecta con daños de importancia muy variada a edificios, carreteras, tuberias y conducciones, entre otros. Concretamente se aportan algunas soluciones para cada caso.

Dentro de la línea de pretender ayudar al técnico de construcción en la amplia gama de todas las ramas que abarca su profesión se ha desarrollado, en el contenido de los sucesivos números de su ya dilatada vida tricentenaria, con mayor o menor extensión, pero prácticamente sin dejar ninguna al margen, aspectos de: maquinaria, confort, higrotermia, aislamientos térmicos y acústicos, iluminación interior y exterior (urbana, de jardines y vial), bienestar, ahorro de energía, corrosión, pliegos de condiciones, precios, potabilización del agua de mar y otros muchos, entre los que aparece hasta el "Léxico de la Construcción" puesto al día e incorporando, por tanto, palabras nuevas que el progreso de la ciencia ha hecho necesarias, a fin de facilitar la comprensión de las técnicas modernas y de los nuevos materiales y sistemas existentes hoy, tales como la coordinación dimensional, la normalización, la industrialización y la prefabricación por procedimientos cerrados o de los «modelos» y abiertos o de los "elementos".

Informes de la Construcción ha sido, además, el portavoz autorizado que nos ha tenido al corriente de la presencia de los investigadores del Instituto Eduardo Torroja en las más importantes organizaciones nacionales e internacionales (construcción y cemento) ya sea como asisten- 


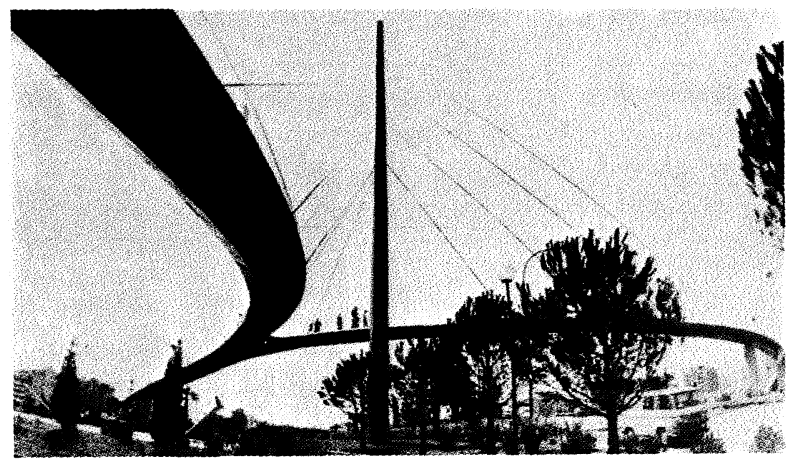

C. Fernández Casado, J. Manterola y L. Fernández Troyano.-Pasarela colgada, en Barcelona (Informes $n .^{\circ} 256$ ).

tes, como ponentes, o como miembros de los Consejos respectivos, incluso, no pocas veces, ostentando la propia presidencia de los mismos.

Por todo lo cual podemos decir, con justa satisfacción, que Informes de la Construcción ha cubierto, a lo ancho y a lo alto de sus páginas, todo el campo de la construcción; ha acogido las más diversas tendencias y opiniones, asi como los nombres de mayor renombre universal.

En realidad ha nacido, ha vivido hasta ahora y esperamos que siga existiendo, para el hombre en el más amplio sentido de la palabra, dado que él es quien crea las obras de arquitectura e ingenieria, él es, también, el que las contempla y las critica $y$, en definitiva, es quien las disfruta.

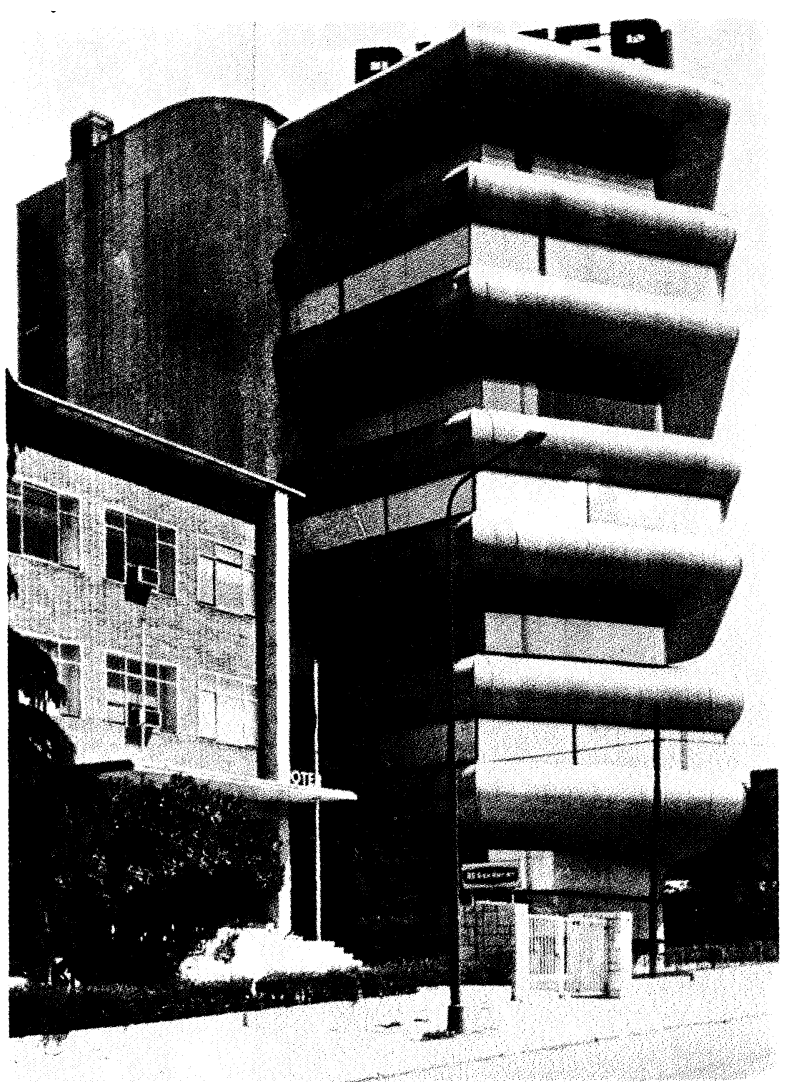

M. Fisac.-Edificio de oficinas en Madrid (Informes $n .^{\circ} 285$ ). 